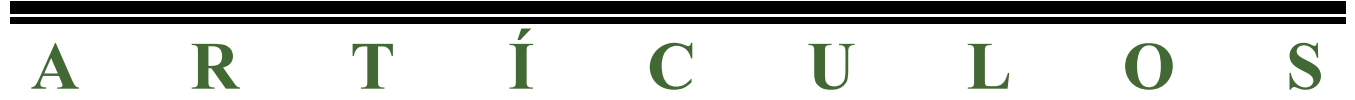




\section{DERECHO PENAL Y FILOSOFÍA DEL DERECHO EN LA REPÚBLICA FEDERAL DE ALEMANIA}

\section{A) DERECHO PENAL Y FILOSOFÍA DEL DERECHO EN LA MODERNA TRADICIÓN ALEMANA}

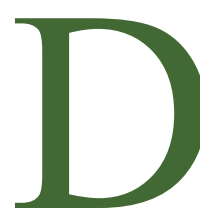

esde los tiempos de esplendor de la Filosofía alemana, es decir, desde la época del Idealismo y la Ilustración, existen estrechas relaciones entre Filosofía, Filosofía del Derecho y Derecho penal. Pero estas relaciones se han ido debilitando poco a poco en este siglo, a partir del momento en que la Filosofía del Derecho ha sido, en cierto modo, superada por sus herederas, la Teoría y la Sociología del Derecho.

Para los principales representantes del Idealismo alemán, Kant y Hegel, la Filosofía del Derecho todavía formaba parte del sistema filosófico general; lo que hoy denominamos «Ciencia dogmática del Derecho» o «Teoría general del Derecho» carecía de autonomía sistemática, recibiendo su contenido y utilidad de su relación con los teoremas filosóficos morales y sociales.

Así, por ej., toda la filosofía sobre la voluntad autónoma y heterómana la trata Kant en sus «Fundamentos sobre Metafísica de las costumbres» (sección segunda). Pero también en este libro discute cuestiones que hoy consideramos características de la «Teoría general del Derecho», dedicando la primera parte al Derecho privado, y la segunda al Derecho público, en el que incluye el Derecho penal y el Derecho de gracia.

Esta integración de Filosofía y Derecho ha beneficiado a las dos disciplinas. Por un lado, porque de este modo los problemas jurídicos quedaron situados en un contexto más amplio y fundamental; por otro lado, porque la filosofía, al hacer filosofía sobre el Derecho o los derechos del individuo en sociedad, recibe -por lo menos, en teoría- una conexión con la praxis (lo que no se puede decir, por ejemplo, de la teoría crítica de la Escuela de Frankfurt, a la que todavía le falta esa conexión con la realidad de las instituciones sociales). 
Pero esta tradición integradora de la Filosofía, la Filosofía del Derecho y la Ciencia jurídica fue perdiéndose a lo largo del siglo XIX. Después de Kant y Hegel se establecieron en el ámbito del Derecho y de la Filosofía del Derecho sistemas que tomaron y desarrollaron los teoremas de estos grandes maestros. Tanto los neohegelianos, como los neokantianos fueron grandes filósofos del Derecho, pero sus reflexiones sobre él mismo ya no procedían de un sistema filosófico universal. Desde el punto de vista profesional, unos eran filósofos, otros juristas. Y en general, se puede decir que en esa época la filosofía del Derecho se estructuró claramente en diversas «escuelas» que se ocupaban de discutir intensamente concretos problemas jurídicos en estrecha vinculación con la Dogmática jurídica que, por aquel entonces, disfrutaba de una gran reputación por su extraordinaria finura y riqueza conceptual heredada de la Escuela Histórica y del Derecho romano.

Todavía una mayor reducción de su ámbito experimentó a principios del siglo XX la filosofía del Derecho, que poco a poco fue siendo sustituida por la «teoría y metodología del Derecho» (como ciencias de la relación entre norma y decisión), por un lado, y la Sociología del Derecho (como ciencia empírica del Derecho), por otro. Estas nuevas ciencias dejaron de preocuparse por las cuestiones tradicionales y buscaron otros ámbitos de discusión. La Filosofía del Derecho pasó a ocuparse sólo de la justificación del Derecho (teoría de los valores, Derecho natural, teoría de la vigencia del Derecho, derecho a la resistencia, etc.), dejando muchas de las cuestiones que tradicionalmente habían sido tratadas dentro de su ámbito, en manos de la Dogmática jurídica; así, por ej., cuestiones tales como la legitimación del Estado o la legitimación de la pena comenzaron a tratarse en el Derecho constitucional o en el Derecho penal. A la Filosofía del Derecho le ocurrió lo que ya antes le había sucedido a la Teología; fue superada por sus propias hijas, que continuaron planteándose las mismas cuestiones pero con sus propios métodos. Con ello surgieron, al mismo tiempo, difíciles problemas de delimitación, que complicaron aún más las relaciones de las «Ciencias jurídicas básicas» entre sí.

La tradición jurídico-filosófica se mantuvo con mayor pureza y éxito en el Derecho penal. Incluso todavía hoy, hay teorías del Derecho penal y de la pena basadas en la filosofía kantiana y en los dos polos que sustentaron esa filosofía: la teoría del conocimiento del idealismo alemán y la filosofía política de la Ilustración. Su mérito histórico ha sido precisamente el de unir ambas líneas de la filosofía idealista y el de hacerlas fructíferas para el 
Derecho penal. Representantes de estas ideas son sobre todo Paul Johann Anselm Feuerbach, Gustav Radbruch, Karl Engisch y Arthur Kaufmann. También yo me siento dentro de esta tradición.

En lo que sigue voy a tratar del significado que esta tradición de la Filosofía idealista puede tener todavía en cuestiones con cretas del Derecho penal.

\section{B) SIGNIFICADO DE LA FILOSOFÍA POLÍTICA DE LA ILUSTRACIÓN PARA EL DERECHO PENAL}

\section{Teoría del conocimiento: la superación del Derecho natural}

La teoría crítica del conocimiento del idealismo alemán, significó, dicho de un modo simple y breve, la superación del Derecho natural clásico. El Derecho natural cosmológico de la tradición aristotélica descansaba en la deducción del deber a partir del ser («monismo metódico»), el orden del deber humano se derivaba así del orden real de la naturaleza. Esta deducción de un orden del deber desde el mundo empírico no fue ya posible a partir de Kant; los neokantianos, con el «dualismo metódico», realizaron importantes restricciones al separar con claridad el ser del deber ser.

El destino del Derecho natural de origen divino característico de la teología de Tomás de Aquino y del pensamiento medieval europeo, estaba indisolublemente unido al destino de una divinidad inmanente; de un ser, por tanto, que no sólo era la fuente incuestionable del puro deber, sino también la que revelaba este deber a las personas. Ciertamente todavía en el siglo XVIII, la filosofía y la teología aceptaban de una forma u otra la idea de Dios, pero ya entonces estaba claro que este Dios no era ya directamente el legislador del orden humano que establecía los deberes.

La Filosofía idealista no hubiera merecido este nombre, si no hubiera creado las bases de otra clase de Derecho natural, del llamado «Derecho natural racionalista».

La ordenación de los deberes como producto de la razón humana, fue la lógica consecuencia de la superación del Derecho natural cosmológico de origen divino, colocando por primera vez en la historia al hombre, como ser responsable y autónomo, en el centro de la Antropología filosófica.

Este Derecho natural racionalista desempeñó un papel muy importante en toda la discusión que sobre la legitimación del 
poder hubo en el siglo XIX. Pero su éxito se debió más a su propia vaguedad que a su viabilidad jurídico-filosófica. La «razón humana» es más un topos argumentativo que una fuente del Derecho. Como bien demuestra la propia historia y la moderna Etnología la razón humana ha dado lugar a muy diversos ordenamientos jurídicos no siempre coincidentes e incluso contradictorios en el tiempo y en el espacio. Esta forma de entendimiento del Derecho natural quizás pudo satisfacer la necesidad que en aquella época había de encontrar un criterio material para de terminar el derecho justo, pero era totalmente insuficiente desde el punto de vista de las exigencias metodológicas que se derivaban de las críticas de la razón pura y a la razón práctica.

\section{Filosofía política: el contrato social}

La respuesta adecuada a la crítica del conocimiento de la filosofía idealista no fue el Derecho natural racionalista, sino las numerosas teorías que sobre el contrato social se formularon por doquier en la Europa de aquel entonces. Sin entrar en particularidades y forzando un poco los aspectos sistemáticos voy a indicar ahora las más importantes directrices en las que se plasmó esta filosofía social y jurídica, así como la idea de libertad de la que partía.

Tras el ocaso de la fundamentación iusnaturalista del Derecho el papel del legislador se modificó de manera fundamental, de simple intérprete del Derecho se convirtió en su creador. Sus prescripciones (leyes) no se legitimaban ya como simples concreciones adaptadas al momento de una ley superior, el Derecho natural, ya que esta ley superior o no existía o, en todo caso, no era aprehensible. El legislador no podía, por tanto, legitimar sus prescripciones por su coincidencia con un Derecho incuestionablemente justo de carácter suprapositivo, sino que tenía que de mostrar la justicia de las mismas por su propio contenido.

La teoría del contrato social fue la respuesta a este problema de legitimación. En el fondo viene a decir que la legitimidad de las prescripciones jurídicas se deriva de los mismos que están sometidos a ellas. El estado natural se transforma en estado jurídico renunciando el ciudadano adulto -capaz de conocimiento- a una parte de su libertad natural para así poder convivir en libertad con los otros ciudadanos que igualmente renuncian a una parte de su libertad.

En un plano horizontal el contrato social significa, por tanto, 
el acuerdo -imaginario- de los ciudadanos en un orden jurídico vinculante para todos.

En el plano vertical el contrato social tiene que ser garantizado institucionalmente. Esta garantía se produce instituyendo contractualmente una autoridad superior a la que le corresponde vigilar que las cláusulas contractuales se cumplan realmente. Pero éste es un problema especialmente precario: el contrato social sólo puede llevarse a cabo si efectivamente se produce la renuncia que hacen los ciudadanos a una parte de su libertad, tal como fue acordado. Quien se exceda en el uso de su libertad o limite un exceso de libertad ajena, estará lesionando los fundamentos del contrato y rompiéndolo en pedazos. Pero, por otra parte, también la autoridad superior puede lesionar los límites impuestos a su actuación, desatender sus funciones o imponer arbitrariamente su voluntad a los ciudadanos, restringiendo, por ej., su libertad más de lo que permite el contrato social. En este caso, muchos de los que defienden la teoría del contrato social admiten también un legítimo derecho de resistencia a la autoridad.

\section{Filosofía del Derecho penal: el aseguramiento de la libertad}

En el contexto de la teoría del contrato social la tarea a cumplir por el Derecho penal se refleja con toda claridad. Para mejor comprender esta tarea, conviene recordar que Feuerbach, el más importante representante de esta concepción, fue al mismo tiempo uno de los más decididos impulsores de la Codificación del Derecho penal influyendo decididamente en la redacción del Código penal bávaro, el más importante Código penal de principios del siglo XIX.

\section{El principio de legalidad}

La idea de la Codificación, es decir, el principio de que los límites de las libertades ciudadanas debían definirse legalmente, constituye el elemento básico de una filosofía del Derecho penal influida por el pensamiento de la Ilustración. Todavía hoy es el principio de legalidad, «nulla poena, nullum crimen sine lege», el criterio fundamental que inspira el Derecho penal del Estado de Derecho, tal como se concibe en la tradición alemana, y es acogido tanto en el Código penal ( $§ 1$ StGB) como en la Constitu- 
ción (art. 103, 28 GG): «Sólo puede ser castigado el hecho cuya punibilidad esté determinada legalmente antes de que haya sido cometido». Con él se garantizan que los límites de la libertad de los ciudadanos sean los mismos y rijan para todos sin excepción, y que, al mismo tiempo, se determinen con precisión tanto para los ciudadanos como para las instituciones. El principio de legalidad se ha convertido así en uno de los símbolos más característicos del Estado de Derecho. En él se concentran las esperanzas de que tanto el sistema como la Administración de Justicia penal sean transparentes, controlables y sinceros.

\section{Orientación a las consecuencias}

Sólo en un punto, por lo demás central, no siguió Feuerbach la filosofía jurídico-penal de Kant: en la justificación de la pena. En este punto, Feuerbach consideraba que la misión de la pena no consistía en alcanzar la Justicia, cualquiera que fueran las consecuencias; sino que sólo era legítima si, tanto en el momento de la conminación legal como en el de su imposición y cumplimiento, conseguía un fin empírico muy concreto: apartar a los posibles delincuentes de cometer delitos en el futuro. Como el propio Feuerbach decía, al individuo inclinado al mal debería atársele a una cadena para que no pudiera llevar a cabo sus perversas inclinaciones; pero como esto, decía, es imposible, habrá que buscar una especie de cadena psicológica que determinara que el individuo que racionalmente calcula las ventajas e inconvenientes de su hecho se abstuviera de cometer delitos. Ello se conseguiría haciendo que la gravedad de la pena que pudiera imponerse fuera más determinante que el posible provecho que pudiera obtenerse con la comisión del delito.

Esta teoría de la «coacción psicológica» demuestra que la filosofía jurídico-penal surgida de la Ilustración había abandonado el conceptualismo orientado input propio de la Filosofía idealista, vinculando el Derecho penal a una orientación output. El parentesco con el utilitarismo es evidente. Esta estructuración preventiva del Derecho penal, completada, al mismo tiempo, con las teorías resocializadoras, reduce enormemente el problema de la legitimación del poder punitivo del Estado, al considerar que la pena, tanto en el momento de su conminación legal, como en el de su imposición, cumple un interés social. Sin embargo, pronto se hizo acreedora de la crítica de la propia filosofía idealista del Derecho penal que, de la mano de Hegel, argumentaba en su contra que no trataba a la persona como un 
ciudadano libre y responsable, sino como a un perro al que se le enseña el palo.

\section{El principio de protección de bienes jurídicos}

En la República Federal de Alemania se discute hoy, en el marco de una «Teoría de la prevención general positiva», si la orientación a las consecuencias en Derecho penal cumple los postulados de la Ilustración o, por el contrario, los debilita. Me parece que la verdad está en el medio: un Derecho penal basado en el contrato social tiene que atender a las consecuencias que produce; pero, por otro lado, esta orientación a las consecuencias debe ser frenada y doblegada por principios normativos, como el de proporcionalidad, el respeto a la dignidad humana y otros principios «formalizadores» del Derecho penal (cfr. infra C. 1). La tercera característica, la vinculación del Derecho penal al principio del bien jurídico, pertenece, sin duda, a las consecuencias de la filosofía política de la Ilustración.

El principio de protección de bienes jurídicos fue elaborado originariamente por Feuerbach y posteriormente desarrollado por Birnbaum y von Liszt, entre otros, como consecuencia de una concepción crítica del Derecho penal. Sólo los intereses humanos (Feuerbach) o, en su caso, los bienes jurídicos (Birnbaum, von Liszt) pueden ser objeto de protección por el Derecho penal. Una conminación penal que sólo tenga como objeto ideología social, es, por tanto, ilegítima. Cuanto mayor sea la vinculación de una conminación penal con un bien jurídico (como, por ej., en los daños patrimoniales o en el homicidio), tanto más intensiva podrá ser, pudiendo incluso castigar la puesta en peligro del bien jurídico (como, por ej., en el delito de incendios).

Por otra parte, el principio de protección de bienes jurídicos exige preguntar si el Derecho penal está realmente en situación de proteger los bienes jurídicos, ayudando, así, a una crítica empírica del Derecho penal.

Desde un principio, la teoría del bien jurídico ha admitido tanto los bienes jurídicos individuales (vida, salud, libertad, honor), como los universales (tráfico fiduciario, Administración de Justicia, Seguridad del Estado).

Pero actualmente se discute si los bienes jurídicos universales deben ser funcionalizados desde el punto de vista de los bienes jurídicos individuales, o a la inversa, distinguiéndose entre teorías individualistas y teorías estatistas. 
En la época del nacionalismo se intentó superar el principio de bien jurídico, sustituyéndolo por el llamado «dogma de la infracción del deber»; pero en los años cincuenta y sesenta volvió a surgir de nuevo con toda su pujanza y fue utilizado con éxito para limitar el ámbito del Derecho penal sexual y de los delitos religiosos.

\section{Formalización del control social jurídico-penal}

Continuando la tradición de la filosofía política de la Ilustración, pero enriqueciéndola y completándola con una consideración sociológica del Derecho penal, las más recientes teorías penales han reformulado la filosofía clásica del Derecho penal. Esta reformulación se puede resumir en la formalización del control social jurídico-penal». Con ello se quiere decir:

A largo plazo, tenemos que partir de que todas las sociedades se caracterizan por el fenómeno del «control social»; es decir, por la existencia de normas sociales, por la sanción de la conducta desviada y por un proceso para aplicar la sanción. En la vida cotidiana el control social se da más o menos formalizado; espontáneo, diferente según el grupo social de referencia, diferenciado por la magnitud de la sanción y con diversos procesos para su aplicación. El control social se da en todas partes: en la familia, en el lugar de trabajo, en la escuela, en las discusiones, en los deportes, etc.; y es imprescindible, tanto en los procesos de socialización y enculturación de los individuos, como para la autodefinición del grupo.

Pero el control social no es sólo estabilizador; también produce daño. Un daño que puede ir desde una simple sonrisa de desprecio hasta la aplicación de la Ley de Lynch, pasando por la reducción del contacto social o la pérdida del puesto de trabajo.

Tanto más grave sea la desviación, tanto más incómodo será para quien la realice; tanto más grave sea la amenaza que esa desviación representa para los demás, tanto más profundo será el conflicto normativo. El control social no sólo afecta virtualmente los derechos humanos de quien ha realizado la conducta desviada, sino también los de la víctima misma, los testigos, etc. El control social, tanto en su forma, como en su contenido, es, por último, un símbolo del nivel cultural de una sociedad.

El Derecho penal se legitima precisamente en la medida en que formaliza el control social. Con los demás medios de control social coincide en que contiene los mismos tres elementos característicos de todo control social: norma, sanción, proceso. Pero 
el Derecho penal debe manejar esos elementos de modo que dentro de lo posible proteja los derechos humanos de todos aquellos que han participado en los casos más graves de conflictos por desviación. Y a eso es a lo que llamo «formalización». Para mí, formalización significa dos cosas:

Por un lado, transparencia y claridad (y con ello, posibilidad de control) de los instrumentos jurídico-penales; por otro, la observancia de determinados principios valorativos.

La claridad y posibilidad de control se corresponden en esencia con el clásico principio de legalidad. Los principios valorativos son, en cambio, muy variados, yendo desde el derecho a la asistencia de letrado y a ser oído en el proceso, hasta el principio de proporcionalidad, pasando por el in dubio pro reo, la prohibición de la reformatio in peius, ne bis in idem, derecho al juez legal, etc.

El Derecho penal se justifica, pues, en la medida en que se consigue formalizar el control social. Por eso, es preocupante la tendencia que se observa actualmente en la República Federal de Alemania a ir abandonando paulatinamente esta tradición formalizadora. De ello nos vamos a ocupar en el siguiente apartado.

C) RECIENTES TENDENCIAS DEL DERECHO PENAL EN LA REPÚBLICA FEDERAL DE ALEMANIA

\section{La actual situación}

En este momento, el Derecho penal, tanto en la teoría como en la praxis, está pasando de la formalización y la vinculación a los principios valorativos a una tecnología social, y paulatinamente se va convirtiendo en un instrumento político, sobre todo en ámbitos como el económico y financiero, medio ambiente, salud pública y seguridad del Estado, y en esta dirección ha dado ya importantes pasos:

1. En el Derecho penal material las reformas actuales se caracterizan por:

- el interés por «combatir» con toda celeridad y urgencia los «problemas» más ampliamente difundidos por los medios de comunicación y que, por eso, son sentidos por la opinión pública como más amenazantes: criminalidad económica y financiera, delito ecológico, delincuencia informática, terrorismo, drogas, pornografía, exportación de mercancías peligrosas, etc.; 
- la protección preferentemente de bienes jurídicos universales tales como la salud pública o el medio ambiente, en lugar de los tradicionales bienes jurídicos individuales;

- el creciente empleo de los delitos de peligro abstracto que prescinden de presupuestos de la pena, tales como el resultado o la causalidad y permiten imponer una pena sólo con que el sujeto realice una determinada acción peligrosa, por ej., presente una solicitud falseando los datos para conseguir una subvención pública;

- la eliminación de los diversos grados de la imputación jurídico-penal (tentativa-consumación; complicidad-autoría);

- un aumento sensible de las penas con evidentes finalidades preventivo-generales intimidatorias.

2. En el Derecho procesal penal, las actuales reformas se caracterizan por su finalidad de acortar, abaratar y desformalizar el proceso, así como por la eliminación de todos los obstáculos que puedan perturbarlo, sean desde el lado inculpado, como del defensor. Las reformas que favorecen los intereses de la víctima se hacen a costa del imputado y del Estado como detentador del monopolio del ius puniendi. Incluso el principio, tan importante en la jurisprudencia penal y constitucional alemanas actuales, de «funcionalidad de la Administración de Justicia penal», favorece ciertamente la efectividad y la economía del proceso, pero a costa de su formalización.

3. Curiosamente, apenas ha habido reformas recientes en el ámbito del Derecho penitenciario; y ello es lógico, pues no se corresponderían con la tendencia sociotecnológica. La praxis penitenciaria se desarrolla ahora más hacia una desformalización de la posición del interno, dando marcha atrás en todo lo que signifique ayuda, favorecimiento o facilidades de su situación, mostrando un desarrollo similar al observado antes respecto al Derecho procesal penal $(\mathrm{C}, 1,2)$.

4. Todas estas tendencias son apoyadas y favorecidas por las teorías actualmente dominantes en Derecho penal. Estas teorías «funcionales» o funcionalistas permiten o favorecen la adaptación de los instrumentos jurídico-penales a las necesidades de la moderna Política criminal. El Derecho penal, entendido por von Liszt, como «barrera infranqueable de la Política criminal», se está convirtiendo en una utopía; lo que actualmente interesa y sirve a un sistema político funcional son conceptos como orientación a las consecuencias, ponderación de intereses en juego, previsión de peligros y programas flexibles de decisión.

5. Igualmente basadas en las tendencias sociotecnológicas 
están las modernas teorías de la pena de la prevención intimidatoria, individual y general. A principios de siglo desaparecieron ya las teorías absolutas de la pena; lo que ahora se considera como pura retribución no es más que prevención general. Las tendencias neoclásicas no han tenido, por tanto, ningún éxito en la República Federal de Alemania (véase infra C. III, 4, lo que se dice respecto a la prevención general positiva). «Fundamentación sociotecnológica» significa:

- tanto el si, como el cómo de la pena dependen de su efecto, no de cuestiones de culpa o de merecimiento;

- por «efecto» se entiende primariamente, las consecuencias de la conminación penal y de la pena en el individuo y, secundariamente, desde el punto de vista estratégico, las consecuencias en la general evolución de la criminalidad;

- el individuo que tiene que ser intimidado o, en su caso, castigado, no es el fin, sino un elemento funcional o paso obligado para la imposición de una pena que tiene una finalidad concreta, evitar la criminalidad en el futuro.

6. También los esquemas cognitivos y normativos (el «clima») que sirven de base y dan origen a estas tendencias, se basan en un planteamiento sociotecnológico; así sucede, por ej., con

- el actual favorecimiento de tópicos como «dominio del futuro» en perjuicio de una respuesta adecuada o, si se quiere, «justa» a las cuestiones actuales (así, por ej., se hace recaer el acento en la «prevención» en lugar de la «retribución»; en el «riesgo» en lugar de la «lesión del bien jurídico»;

- la fe de la comunidad en la fuerza configuradora de la realidad que se atribuye al Derecho penal y en la posibilidad de conseguir con él las consecuencias que se pretenden;

- la legitimación de las intervenciones por las consecuencias favorables que producen, y no por la «justicia» de las mismas: orientación out put;

- y finalmente, la tendencia a sustituir en las teorías legitimadoras los planteamientos personalistas por planteamientos sociales.

\section{Perspectivas evolutivas}

La situación que se acaba de describir tiene su origen en la «dialéctica de lo moderno», es decir, es consecuencia de la lucha 
contra un Derecho penal moralizador, que se ha llevado a cabo con las armas de la Filosofía política de la Ilustración. La guerra se ha ganado y el enemigo ha sido vencido. Pero el actual problema en la República Federal de Alemania no es el Derecho penal moralizador, sino un Derecho penal inspirado en las modernas técnicas sociológicas.

Las armas que antes se utilizaron contra el Derecho penal moralizador se han independizado; los signos han cambiado.

1. Así, por ej., el concepto de protección de bienes jurídicos, que originariamente tuvo una función estratégica en las tendencias descriminalizadoras; y en este sentido se utilizó para de rogar aquellas conminaciones penales que no tenían como objeto la protección de algún concreto bien jurídico o que únicamente pretendían proteger concepciones morales, se utiliza actualmente con una finalidad distinta, como un criterio para criminalizar.

2. Lo mismo ha sucedido con los fines de la pena (por lo menos, en la medida en que se conciban preventivamente en el sentido que lo hizo Feuerbach, supra B, III, 2). Originariamente se utilizaron contra todas aquellas intervenciones jurídico-penales que, bien no producían ninguna consecuencia o incluso eran contrarias a ello; que no tenían, por tanto, «ningún fin». Por eso, se entendía que la «pura» retribución, no era suficiente para legitimar una intervención en la libertad o en la propiedad; al principio de culpabilidad se le otorgaba una función limitadora y no fundamentadora de la pena; y dentro de estos límites era posible pretender consecuencias empíricas favorables (corrección, intimidación). En cambio, hoy el concepto de prevención tiende a convertirse en un modelo de intervención que supera y descualifica como obstáculos para una orientación social efectiva los principios de proporcionalidad, igualdad de trato, o legalidad (es decir, los principios valorativos del Derecho penal formalizado a los que antes hacíamos referencia, supra B, III, 4).

3. Todas estas tendencias colocan al Derecho penal ante una renovada y fortalecida necesidad de legitimación. Ya no son suficientes las justificaciones deontológicas de la conminación penal y de la pena; ahora hay que demostrar que el sistema, desde el punto de vista sociotecnológico, funciona también realmente, que de modo relevante produce consecuencias favorables e impide las desfavorables. La orientación a las consecuencias tiene como efecto que el sistema jurídico-penal permanente y públicamente deba afirmarse como instrumento político técnicamente eficaz.

4. Estas expectativas no pueden ser cumplidas por el Dere- 
cho penal, o sólo de un modo insuficiente; pero ante esta situación el sistema actual no reacciona retirando los planteamientos sociotecnológicos, sino manteniéndolos y difuminándolos. El ejemplo más gráfico de ello es una Política criminal simbólica que -en contra de la opinión de los expertos que consideran que la agravación de las conminaciones penales no aumenta el efecto intimidatorio, y que denuncian los «déficits del sistema penitenciario»- consigue de todos modos que el legislador reconozca con rapidez en la opinión pública una «necesidad de actuación» y que la satisfaga con prontitud. Pero esta ganancia simbólica cuesta cara y se paga con una pérdida de la credibilidad y la justicia del Derecho penal que, de algún modo defrauda las expectativas de los ciudadanos.

\section{Consecuencias}

Lo que hoy se critica cada vez con mayor contundencia no es ya el Derecho penal moralizador, sino el inspirado en la moderna tecnología social, frente al que hay que resucitar las viejas tradiciones «morales» orientadas a la Justicia, la fragmentariedad y la persona y, en relación con los demás sistemas de control social, recuperar y acentuar las peculiaridades que caracterizan el sistema jurídico-penal.

1. Sería anacrónico volver a una fundamentación absoluta de la pena y limitarse a los bienes jurídicos clásicos. Esto sería contrario a los específicos problemas de legitimación del moderno Estado y los problemas de orientación de la moderna «sociedad de riesgos». El acuerdo normativo social puede tanto experimentar como constituir hoy un grave problema (destrucción del medio ambiente, abuso de drogas, criminalidad organizada, etc.), con el que se tiene que enfrentar -guardando las distancias- el Derecho penal, tratando racionalmente lo irracional.

2. El Derecho penal tiene también que recuperar su credibilidad y su prestigio ante los ciudadanos, a los que no debe engañar con falsas promesas. Ello supone que continúe y se intensifique la investigación de los efectos reales de la intervención jurídico-penal, y significa que no se pretenden consecuencias que no pueden ser constatadas y que en los programas de decisión se tengan en cuenta las consecuencias accesorias desfavorables. Un Derecho penal legitimado por las consecuencias no puede sustraerse a la legitimación. En mi opinión, un Derecho penal que no utiliza el concepto de consecuencia como una simple estrategia simbólica, sino que lo elabora metodológicamente y del 
modo más honesto posible, vuelve en muchos ámbitos a la legitimación input.

3. Ante los nuevos problemas que amenazan, tan complejos y difusos, el Derecho penal debe continuar manteniendo y configurando su tarea formalizadora del control social (supra B, III,

4). Esto quiere decir en especial que:

- sólo deben protegerse los bienes jurídicos que puedan ser descritos concretamente y asegurados con sus instrumentos (lo que es bastante problemático en los ámbitos relacionados con las drogas y el medio ambiente);

- se mantenga el principio de la imputación individual también en los casos más complejos, como sucede en aquellos en los que se encuentran involucradas grandes empresas;

- se siga preservando el carácter de la protección jurídico penal como última ratio (fomentando, en consecuencia, otras formas de protección como el seguro o la reparación de daños);

- se defiendan los principios valorativos como el de legalidad o el in dubio pro reo, frente a los intereses políticos en pro de la efectividad;

- se considere que estos principios son irrenunciables y permanentes, como símbolos de nuestra cultura, incluso en «caso de necesidad» o de enfrentamiento con intereses político-criminales.

4. La teoría de la pena tiene que poner los intereses preventivos en una relación normativa, justificándolos y limitándolos también al mismo tiempo. Una aspiración de esta clase podría quizás conseguirse con una teoría de la prevención general positiva, para la que la pena no es pura adaptación (y mucho menos intimidación), sino la afirmación pública y el aseguramento de las normas fundamentales (también de las normas formalizadoras que recomiendan en algunos casos la descriminalización, la prudencia, la protección jurídica frente a la informática, el perdón y el olvido).

(Trad. de Francisco Muñoz Conde) 